\title{
ENRAIZAMENTO IN VITRO DO PORTA-ENXERTO DE MACIEIRA - M9 EM FUNÇÃO DA VEDAÇÃO, SACAROSE E MATERIAL DE SUPORTE NO MEIO DE CULTURA
}

\section{IN VITRO ROOTING OF THE APPLE TREE ROOTSTOCK - M9 RELATED TO SEAL, SUCROSE AND SUPPORT MATERIAL IN THE CULTURE MEDIUM}

\author{
Joseane Almeida de SOUZA ${ }^{1}$ \\ Lorena Pastorini DONINI \\ Luciane Couto da SILVA ${ }^{2}$ \\ Maria Goreti Senna CORRÊA ${ }^{3}$ \\ Márcia Wulff $\mathrm{SCHUCH}^{4}$
}

\begin{abstract}
RESUMO
Este trabalho teve como objetivo determinar o melhor material de suporte, tipo de vedação dos frascos e concentração de sacarose, visando o enraizamento in vitro do porta-enxerto de macieira M-9. O meio de cultura usado foi o MS, acrescido de ácido indolbutírico-AIB (5 ?M). Os tratamentos consistiram-se no uso de dois tipos de material de suporte (ágar e vermiculita); vedação de frascos (algodão e papel alumínio) e da presença ou ausência de sacarose no meio de cultura. Constatou-se que o ágar promoveu o melhor desempenho para a percentagem de enraizamento, sendo superior à vermiculita em meio de cultivo com sacarose. A vedação dos frascos com algodão promoveu maior número médio de raízes e porcentagem de enraizamento em meio de cultivo com adição de sacarose.
\end{abstract}

Palavras-chave : micropropagação, ágar, vermiculita, algodão, papel alumínio, Malus domestica.

\begin{abstract}
The objective for this study was to evaluate two supportand two of flask covers and the effect of sucrose on the in vitro rooting of M- 9 apple rootstock. The culture medium used was MS, added of indole-3-butyric acid-IBA $(5 \mu \mathrm{M})$. The treatments consisted of two support (agar or vermiculite); flask cover (cotton-wool or aluminum foil) and with or without addition of sucrose to the culture media. In culture medium with sucrose, it was observed higher rooting percentage with agar than that of vermiculite. The flasks covered with cotton-wool had higher average of root number per plantlet as well as higher rooting percentage in the culture medium withsucrose.
\end{abstract}

Key-words : micropropagation, agar; vermiculite; cotton-wool; aluminum foil; Malus domestica.

\footnotetext{
${ }^{1}$ Doutoranda do Curso de Pós-Graduação em Agronomia, área de concentração em Fruticultura de Clima Temperado, Faculdade de Agronomia Eliseu Maciel (FAEM), Universidade Federal de Pelotas (UFPel), CP 354, 96010-900, Pelotas, RS. E-mail: joseas@ufpel.tche.br . Autor para correspondência.

${ }^{2}$ Mestre em Ciências, FAEM/UFPel, Pelotas, RS.

${ }^{3}$ Doutoranda do Curso de Pós-Graduação em Agronomia, área de concentração em Produção Vegetal, FAEM/UFPel, Pelotas, RS

${ }^{4}$ Engenheira Agrônoma, Dra., Professora do Departamento de Fitotecnia, FAEM/UFPel. Caixa Postal 354, 96010-900, Pelotas, RS. E-mail: marciaws@ufpel.tche.br
} 
SOUZA, J. A. de. et al. Enraizamento in vitro...

\section{INTRODUÇÃO}

A micropropagação é uma tecnologia bastante interessante no setor de produção de mudas frutíferas, principalmente na obtenção de portaenxertos. O porta-enxerto M-9 é o mais utilizado na região Sul do país em pomares de alta densidade, devido ao efeito ananizante sobre a cultivar copa, o que facilita o manejo (PEDROTTI e VOLTOLINI, 2001). Desta forma, protocolos de micropropagação definidos, eficientes e de menor custo para este portaenxerto são necessários. O desenvolvimento de sistemas de micropropagação fotoautotróficos, isto é, sem adição de sacarose no meio de cultura e sob condições ambientais que promovam a fotossíntese na planta, surgem como possibilidades, de grande potencial a fim de aumentar a eficiência e reduzir os custos, viabilizando a micropropagação dessa espécie em âmbito comercial.

Durante as fases de cultivo in vitro, as plantas crescem sob condições especiais, em ambientes fechados, sem trocas gasosas, com alta umidade do ar, baixa intensidade luminosa e utilizando açúcares do meio como fonte de carbono e energia (PREECE e SUTTER, 1991; SCIUTTI e MORINI, 1993; POSPÍSILOVÁ et al., 1999). O desenvolvimento fotoautotrófico de espécies de plantas clorofiladas pode ser promovido através do aumento da concentração de $\mathrm{CO}_{2}$ e intensidade luminosa, através da diminuição da umidade relativa dentro do frasco e através do uso de material de suporte poroso ou fibroso (KOZAI e KUBOTA, 2001). Dentre os principais fatores que irão determinar a qualidade do microambiente dentro dos frascos, o tipo de tampa utilizado é um deles, pois irá determinar o nível de troca gasosa com o ambiente externo.

$\mathrm{Na}$ fase de enraizamento, a planta necessita de energia, que pode ser oriunda da fotossíntese ou da fonte de açúcar presente no meio. O carbono adicionado ao meio de cultura serve como fonte de energia e vai influenciar na fisiologia da planta, diferenciação e crescimento de tecidos e órgãos (CALVETE et al., 2002). Por outro lado na micropropagação fotoautotrófica, a formação, o desenvolvimento e o crescimento de raízes in vitroé fisiologicamente e morfologicamente normal. O cultivo em meio sem sacarose apresenta a vantagem do baixo risco de contaminação e o cultivo com material de suporte poroso permite que as plantas sejam aclimatizadas juntamente com o material de suporte, diminuindo o dano às raízes (KOZAI e KUBOTA, 2001; KUBOTA e TADOKORO, 1999). A utilização mais ampla da micropropagação tem sido limitada pela freqüência de danos e perdas de plantas, quando são transferidas das condições in vitro para ex vitro, sendo necessário aperfeiçoar as fases de cultivo in vitro, como a fase de enraizamento, para obtenção de sucesso na aclimatização (CALVETE et al., 2002; ROGALSKI et al., 2003). O uso de substratos alternativos para o enraizamento, visando a obtenção de um sistema radicular mais apropriado para a adaptação da planta em casa de vegetação, já foi testado em diversos trabalhos e pode ser útil em sistemas intensivos de micropropagação. GRATTAPAGLIA e MACHADO (1998) mencionam que a vermiculita, perlita ou espumas de poliuretano embebidas com meio líquido podem ser alternativas mais baratas e dar melhores resultados que o ágar.

Este trabalho teve como objetivo avaliar o enraizamento in vitro de porta-enxerto de macieira M-9, em meio com diferentes materiais de suporte, na presença ou ausência de sacarose e sob diferentes formas de vedação dos frascos.

\section{MATERIAL E MÉTODOS}

O trabalho foi realizado no Laboratório de Micropropagação de Plantas Frutíferas, Departamento de Fitotecnia da Faculdade de Agronomia Eliseu Maciel, da Universidade Federal de Pelotas, RS. Microestacas de 3 a $4 \mathrm{~cm}$ do portaenxerto $M-9$, extraídos de material cultivado in vitro, foram utilizados como explantes. Os tratamentos constituíram-se de dois tipos de material de suporte (ágar e vermiculita), dois tipos de vedação dos frascos (algodão e papel alumínio) e presença ou ausência de sacarose no meio de cultivo.

O meio de cultura utilizado foi o MS (MURASHIGE e SKOOG, 1962), acrescido de 100 $\mathrm{mg} \mathrm{L}^{-1}$ de mio-inositol, $30 \mathrm{~g} \mathrm{~L}^{-1}$ de sacarose e 5 ? M de AIB, sendo o $\mathrm{pH}$ ajustado para 5,8 antes da inclusão do ágar (Vetec $\left.{ }^{\circledR}\right)$ na concentração de $6 \mathrm{~g} \mathrm{~L}$ ${ }^{1}$ ou da vermiculita (granulometria média) $12 \mathrm{~g} \mathrm{~L}^{-1}$ sendo, posteriormente, autoclavado a $121^{\circ} \mathrm{C}$ e 1,5 atm por 20 minutos. Foram utilizados frascos de 250 $\mathrm{mL}$ com $30 \mathrm{~mL}$ de meio de cultura. Após a inoculação, os explantes permaneceram em sala de crescimento com fotoperíodo de 16 horas, temperatura de 25 ? 2 C e densidade de fluxo de fótons do período de luz de $27 ? \mathrm{~mol} \mathrm{~m}^{-2} \mathrm{~s}^{-1}$.

Utilizou-se o delineamento experimental inteiramente casualizado em esquema fatorial $(2 \times 2$ $x 2$ ), totalizando 8 tratamentos, com quatro repetições de cinco explantes. Aos 40 dias de cultivo, avaliouse a porcentagem de enraizamento, comprimento médio da maior raiz, número médio de raízes e a massa fresca das plantas. Os dados foram submetidos à análise de variância e as médias dos tratamentos comparadas pelo teste de Duncan em nível de $5 \%$ de probabilidade de erro.

\section{RESULTADOS E DISCUSSÃO}

Para a variável porcentagem média de enraizamento houve diferença estatística para o tipo de material de suporte e para a interação entre tipo de vedação dos frascos e presença ou ausência de sacarose no meio (Tabela 1). O teste de Duncan evidenciou que o ágar foi superior a vermiculita, apresentando porcentagem de enraizamento de 67,8 e 37,4, respectivamente. A vedação dos frascos com algodão promoveu resultados superiores em relação aos obtidos com a vedação com papel alumínio. Isso 
ocorreu provavelmente devido a maior troca gasosa proporcionado pela vedação com algodão, resultando na redução da umidade relativa e na menor concentração de etileno no frasco de cultivo, proporcionando, desta forma melhores condições para realização da fotossíntese, possibilitando de

SOUZA, J. A. de. et al. Enraizamento in vitro... certa forma o desenvolvimento autotrófico (KOZAI e KUBOTA, 2001). Resultados semelhantes, com relação ao material de suporte, foram encontrados por HOFFMANN et al. (2001), onde foi observado que a indução do enraizamento nos porta-enxertos Marubakaido e M-26 foi mais eficiente em ágar, seguido da mistura vermiculita + ágar.

TABELA 1 - Percentagem de enraizamento do porta-enxerto de macieira M-9, após 40 dias de cultivo in vitroem meio MS na presença e ausência de sacarose e diferentes formas de vedação dos frascos. UFPel, Pelotas, RS. 2007.

\begin{tabular}{lcc}
\hline \multicolumn{1}{c}{ Tipo de vedação } & \multicolumn{2}{c}{ Porcentagem de enraizamento* } \\
\cline { 2 - 4 } dos frascos & Com sacarose & Sem sacarose \\
Algodão & 88,88 a A & 60,98 a B \\
Papel Alumínio & 76,72 a A & 0,34 b B \\
\hline CV (\%) & & 36,78 \\
\hline
\end{tabular}

Para a variável número médio de raízes observou-se que o tipo de vedação dos frascos e a interação do tipo de material de suporte versus presença ou ausência de sacarose no meio foi significativa. A vedação com algodão proporcionou melhores resultados em relação ao alumínio, apresentando número médio de raízes igual a 3,3 na vedação com algodão e 1,4 com papel alumínio. Os resultados promovidos pelo ágar foram superiores aos obtidos com a vermiculita em meio suplementado com sacarose (Tabela 2). Testando diferentes concentrações de sacarose no enraizamento in vitro de morangueiro CALVETE et al. (2002) observaram que o aumento da concentração de sacarose promoveu um incremento de biomassa, tanto na parte aérea como no sistema radicular, das mudas de morangueiro.

TABELA 2 - Número médio de raízes do porta-enxerto de macieira M-9, após 40 dias de cultivoin vitro em meio MS na presença e ausência de sacarose e sob diferentes materiais de suporte. UFPel, Pelotas, RS. 2007.

\begin{tabular}{|c|c|c|}
\hline \multirow{2}{*}{ Tipo de solidificante } & \multicolumn{2}{|c|}{ Número médio de raízes* } \\
\hline & Com sacarose & Sem sacarose \\
\hline $\begin{array}{l}\text { Ágar } \\
\text { Vermiculita }\end{array}$ & $\begin{array}{c}7,85 \text { a } A \\
1,69 \text { b A }\end{array}$ & $\begin{array}{l}0,91 \text { a B } \\
0,50 \text { a B }\end{array}$ \\
\hline CV (\%) & & \\
\hline
\end{tabular}

*Médias seguidas de mesma letra minúscula nas colunas e maiúscula nas linhas não diferem entre si pelo teste de Duncan ao nível de $5 \%$.

Para as variáveis comprimento médio da raiz e massa fresca das plantas houve diferença significativa na interação entre o tipo de material de suporte e a presença ou ausência de sacarose no meio, sendo que o ágar promoveu respostas superiores à vermiculita, em meio de cultivo acrescido de sacarose (Tabela 3). A presença do ágar provavelmente tenha disponibilizado uma maior quantidade de sacarose ao explante, devido ao maior contato das raízes com o meio, em relação a vermiculita. A massa fresca da parte aérea e do sistema radicular foi maior quando utilizaram ágar na concentração de 3 e $6 \mathrm{~g} \mathrm{~L}^{-1}$ como suporte no meio de cultivo, sendo que a vermiculita promoveu os piores resultados (PASQUAL et al., 2000). A vermiculita foi o substrato que apresentou menor eficiência no desenvolvimento in vitro de raízes de dois porta-enxertos de macieira, atribuindo esse fato aos grandes espaços porosos existentes na vermiculita, o que dificulta a aderência dos explantes (HOFFMANN et al., 2001). 
SOUZA, J. A. de. et al. Enraizamento in vitro...

TABELA 3 - Comprimento médio da raiz e massa fresca das plantas do porta-enxerto M-9, após 40 dias de cultivo in vitroem meio MS na presença e ausência de sacarose e sob diferentes materiais de suporte. UFPel, Pelotas, RS. 2007.

\begin{tabular}{cccc}
\hline & Variáveis & $\begin{array}{c}\text { Comprimento médio da raiz mais } \\
\text { desenvolvida }(\mathrm{cm})^{*}\end{array}$ & $\begin{array}{c}\text { Massa fresca } \\
\text { das plantas }(\mathrm{g})^{*}\end{array}$ \\
$\begin{array}{c}\text { Com } \\
\text { sacarose }\end{array}$ & $\begin{array}{c}\text { Agar } \\
\text { Vermiculita }\end{array}$ & $4,10 \mathrm{a}$ & $1,84 \mathrm{a}$ \\
Sem & Agar & $0,32 \mathrm{~b}$ & $0,90 \mathrm{~b}$ \\
sacarose & Vermiculita & $0,37 \mathrm{a}$ & $0,48 \mathrm{a}$ \\
& CV (\%) & $0,07 \mathrm{a}$ & $0,46 \mathrm{a}$ \\
\end{tabular}

*Letras distintas dentro de cada tratamento, na coluna, diferem entre si pelo teste de Duncan ao nível de 5\%.

\section{CONCLUSÕES}

O ágar possibilitou maior porcentagem de enraizamento e promoveu maior número e comprimento médio das raízes e maior massa fresca das plantas quando associado à presença de sacarose, sendo que a vedação dos frascos com algodão favoreceu o enraizamento em meio com adição de sacarose.

\section{REFERÊNCIAS}

1. CALVETE, E.O.; KÄMPF, A.N.; SUZIN, M. Concentração de sacarose no enraizamento in vitro de morangueiro. Horticultura Brasileira, Brasília, v. 20, n. 2, p. 186-191, 2002.

2. GRATTAPAGLIA, D.; MACHADO, M.A. Micropropagação. In: TORRES, A.C.; CALDAS, L.S.; BUSO, J.A. Cultura de tecidos e transformação genética de plantas. Brasília: Embrapa-SPI/Embrapa-CNPH, 1998. p.183-260.

3. HOFFMANN, A.; PASQUAL, M.; CHALFUN, N.N.J.; VIEIRA, S.S.N. Substratos na indução e desenvolvimento in vitro de raízes em dois porta-enxertos de macieira. Pesquisa Agropecuária Brasileira, Brasília, v. 36, n. 11, p. 1371-1379, 2001.

4. KOZAI, T.; KUBOTA, C. Developing and photoautotrophic micropropagation system for woody plants. Journal of Plant Research, Tokyo, v. 114, p. 525-537, 2001.

5. KUBOTA, C.; TADOCORO, N. Workshop on bioreactor technology control of microbial contamination for large-scale photoautotrophic micropropagation. Society for In Vitro Biology, v. 35, p. 296-298, 1999.

6. MURASHIGE, T.; SKOOG, F. A revised medium for rapid growth and biossay with tabacco tissue cultures. Physiologia Plantarum, Kobenhavn, v. 15, p. 473-497, 1962.

7. PASQUAL, M.; SILVA, A.B. da.; MACIEL, A.L.R.; PEREIRA, A.B.; CAVALCANTE-ALVES, J.M. Enraizamento in vitro de um porta-enxerto de macieira em diversos substratos. Scientia Agricola, Piracicaba, v. 57, n. 4, p. 781-784, 2000.

8. PEDROTTI, E.L.; VOLTOLINI, J.A. Enraizamento ex vitroe aclimatização do porta-enxerto de macieira M9. Revista Brasileira de Fruticultura, Jaboticabal, v. 23, n. 2, p. 234-239, 2001.

9. POSPÍSILOVÁ, J.; TICHÁ, I.; KADLECEK, P.; HAISEL, D.; PLZÁKOVÁ, S. Acclimatization of micropropagated plants to ex vitro conditions. Biologia Plantarum, Prague, v. 42, n. 4, p. 481-497, 1999.

10. PREECE, J.E. SUTTER, E.G. Acclimatization of micropropagated plants to the greenhouse and field. In: DEBERGH, P.C.; ZIMMERMAN, R.H. Micropropagation: tecnology and application. Kluwer: Dordrecht, 1991. p. 71-93.

11. ROGALSKI, M.; MORAES, L.K.A. de.; FELISBINO, C.; CRESTANI, L.; GUERRA, M.P.; SILVA, A.L. Aclimatização de portaenxertos de Prunus sp. micropropagados. Revista Brasileira de Fruticultura, Jaboticabal, v. 25, n. 2, p. 279-281, 2003.

12. SCIUTTI, R.; MORINI, S. Effect of relative humidity in vitro culture on some growth characteristics of a plum rootstock during shoot proliferation and on plantlet survival. Advances in Horticultural Science, Firenze, v. 7, p. 153-156, 1993.

Recebido em 19/01/2007

Aceito em 19/04/2007 